\title{
Geophysical Surveys at Khirbat Faynan, an Ancient Mound Site in Southern Jordan
}

\author{
Alexandre Novo, ${ }^{1}$ Matthew L. Vincent, ${ }^{2}$ and Thomas E. Levy ${ }^{2}$ \\ ${ }^{1}$ Geostudi Astier, via A. Nicolodi 48, 57121 Livorno, Italy \\ ${ }^{2}$ Department of Anthropology \& California Institute for Telecommunications and Information Technology (Calit2), \\ University of California, San Diego, CA 92093, USA \\ Correspondence should be addressed to Alexandre Novo, novo@geoastier.it \\ Received 16 April 2012; Accepted 4 July 2012 \\ Academic Editor: Nicola Masini
}

Copyright () 2012 Alexandre Novo et al. This is an open access article distributed under the Creative Commons Attribution License, which permits unrestricted use, distribution, and reproduction in any medium, provided the original work is properly cited.

Faynan in Jordan contains the largest copper ore resource zone in the southern Levant (Israel, Jordan, Palestinian territories, Lebanon, Syria, and the Sinai Peninsula). Located $50 \mathrm{~km}$ southeast of the Dead Sea, it is home to one of the world's best-preserved ancient mining and metallurgy districts encompassing an area of ca. $400 \mathrm{~km}^{2}$. During the past three decades, archaeologists have carried out numerous excavations and surveys recording hundreds of mines and sites related to metallurgical activities that span the past 10 millennia. Khirbat Faynan (Biblical Punon), is situated in the main Faynan Valley and is the largest (ca. 15 ha) settlement site in the region and has remained unexcavated until 2011. As Jordan's most southern mound site with indications of widespread ancient architecture, we employed a suite of noninvasive geophysical survey methods to identify areas suitable for excavation. Earlier geophysical surveys were carried out in the Faynan region by our team in the late 1990s when only EMI (electromagnetic induction) proved successful, but with relatively poor resolution. As reported here, by 2011, improvements in data processing software and 3D ERT (electrical resistivity tomography) sampling protocols made it possible to greatly improve the application of noninvasive geophysical surveying in this hyperarid zone.

\section{Introduction}

Improvements in processing software and sampling protocols for shallow geophysical prospecting make it a key tool for initiating archaeological exploration. In terms of research design, geophysics have increasingly become an essential part of the methodology for planning archaeological excavation in a number of unexplored regions around the world $[1,2]$. As part of a long-term archaeological study of the role of mining and metallurgy in the evolution of societies from the Neolithic period (ca. 8000 BC-6000 BC) to Islamic times (7th c. CE-early 20th c. CE) in Jordan's Faynan copper ore district, the University of California, San Diego (UCSD) Edom Lowlands Regional Archaeology Project (ELRAP) conducted intensive systematic surveys and large-scale excavations at sites spanning all these periods. From 20022010, the primary research focus was on the formative Iron Age (ca. 1200-500 BCE) when the first historical state-level societies evolved in this part of the eastern Mediterranean and the ancient Near East's first industrial revolution took place. Large-scale excavations were carried out at Khirbat en-Nahas (ca. 10 hectares), the largest copper ore processing and smelting site in the region (cf. [3]), smaller production sites [4], fortresses [5], mining complexes [6], and other sites making it possible to reconstruct the Iron Age "metallurgical landscape" of this natural resource zone [7]. While it was possible to reconstruct the network of ore exploitation, processing, and manufacture, the location and nature of political and economic center remains a mystery. Based on previous surveys and research in the main Wadi Faynan valley, more researchers believe that a large (ca. 15 hectares) ancient mound site called Khirbat Faynan (known as Punon in the Hebrew Bible and Phaino in late Roman/Byzantine texts) may have been that center during the Iron Age [8]. In 2011, the UCSD ELRAP team initiated the first multiyear largescale excavation project at this site, the most southern ancient 
mound site in Jordan. To initially tackle the excavation of this site, a geophysical survey was carried out that helped guide the selection of the first excavation at the site.

Khirbat Faynan (Figure 1) is a multiperiod site located where Wadi Dana and Wadi Ghuwayr meet (becoming Wadi Faynan) in the hyperarid Saharo-Arabian vegetation zone [9]. The site has a significant amount of well-preserved Roman and Byzantine ruins still visible. Previously, the Deutsches Bergbau Museum under Andreas Hauptman and the Council for British Research in the Levant (CBRL) under Graeme Barker and colleagues surveyed the site $[8,10]$. To facilitate a Paleoenvironmental study in the region, a small sounding was made north of the site behind a large wall structure called the "Barrage" $[11,12]$. The site's prominent position next to the convergence of the two previously mentioned wadis sets it apart in the landscape, and it is easy to postulate that it controlled the agricultural field systems to the north and west, and access to the road leading from the copper-ore-rich lowlands to the highland plateau to the east. While many have suggested the role of the "Khirbat" in the region, there still lacks archaeological evidence to fully support these postulations. The 2011 ELRAP expedition was codirected by Thomas Levy and Mohammad Najjar to begin to answer questions concerning the socioeconomic function of the site during the Iron Age. With several significant periods of occupation, it will require several seasons of excavation to fully articulate and understand the site. As part of this expedition, a geophysical survey of the site and its immediate surroundings was conducted in order to create a geological profile of the tell (Arabic: ancient mound site) and identify primary candidates for excavation.

Full characterization of archaeological sites by conventional archaeological techniques can take years. Moreover, drilling and excavations, the most often applied methods for archaeological assessment, are ground disturbing. Therefore, nondestructive geophysical techniques have been used to detect and map underground features in a fast and noninvasive manner [13-16]. Among these techniques and based on previous results in the same area [17], we decided to use EMI (electromagnetic induction) and ERT (electrical resistivity tomography). Electromagnetic techniques have been used for archaeological investigations of different sites [18, 19], including places with similar conditions in the Middle East $[20,21]$. Similarly, resistivity surveying has commonly used in noninvasive archaeological prospection $[22,23]$. ERT is quite popular in archaeological investigations [24-27]. The success of the method depends on the difference between the resistivity properties of the potential archaeological targets (walls, roads, buildings, etc.) and the surrounding environment [25]. In recent years, 3D ERT is being increasingly used because it provides a three-dimensional view of the subsoil resistivity. Besides, this technology is considered well-suited for mapping Near Eastern tell sites [28].

The combination of EMI and ERT methods provides a flexible approach for planning archaeological excavations [29]. Our aim was to survey buried structures, especially Iron Age ones, around the site. This paper shows the preliminary results of our archaeogeophysical investigations at Khirbat Faynan undertaken in 2011. After a brief description of the

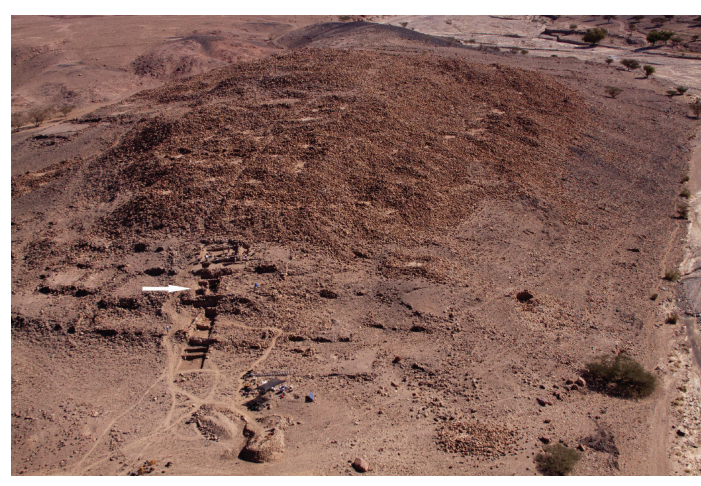

FIGURE 1: Aerial view of Khirbat Faynan looking east showing the excavation trench and excavators. Geophysical surveys were made around the entire site. Scale, note that the trench is $40 \mathrm{~m}$ in length from west to east. Arrow indicates the location of 3D ERT survey (photo, UCSD Levantine Archaeology Lab).

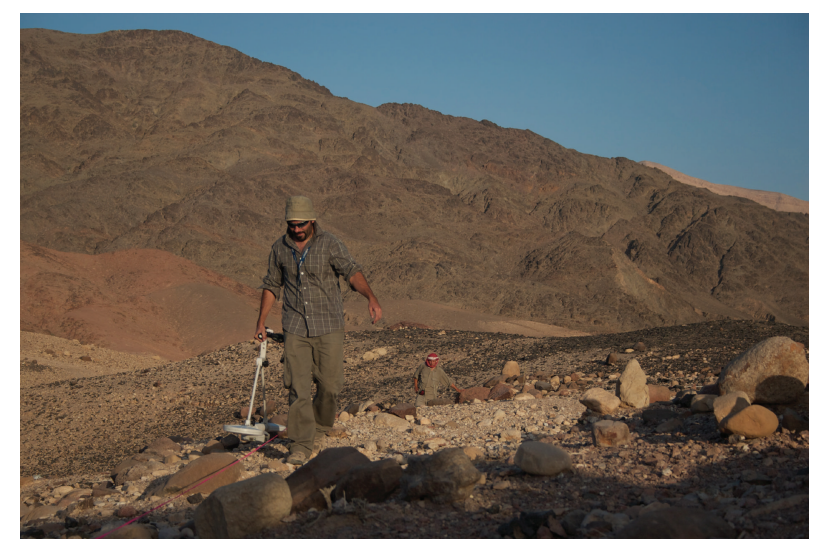

FIGURE 2: Operator follows the string to ensure straight profiles on the slopes of the site of Khirbat Faynan, Jordan. The instrument (photo, M. L. Vincent, UCSD Levantine Archaeology Lab) is kept at a constant distance from the ground surface.

area and past results of the ongoing project, we describe our survey strategies and data processing methods and offer an overview of our findings to date.

\section{Methodologies}

Conditions around the site of Khirbat Faynan make some of the more successful techniques such as GPR (Ground Penetrating Radar) nearly impossible to employ. The ground surface is generally covered with debris from earlier occupation that would have to be cleared before any survey could take place. The process of clearing rocks would not only be expensive in terms of time required to complete such a task, but would also be potentially invasive as it might put at risk exposed architecture which is not always immediately visible among the rock debris. It was decided that the next best options were EMI and ERT, both being well suited for the difficult terrain. These techniques allow for the characterization of the subsoil as well as the ability to detect anomalies that could be associated with buried structures or artifacts. 


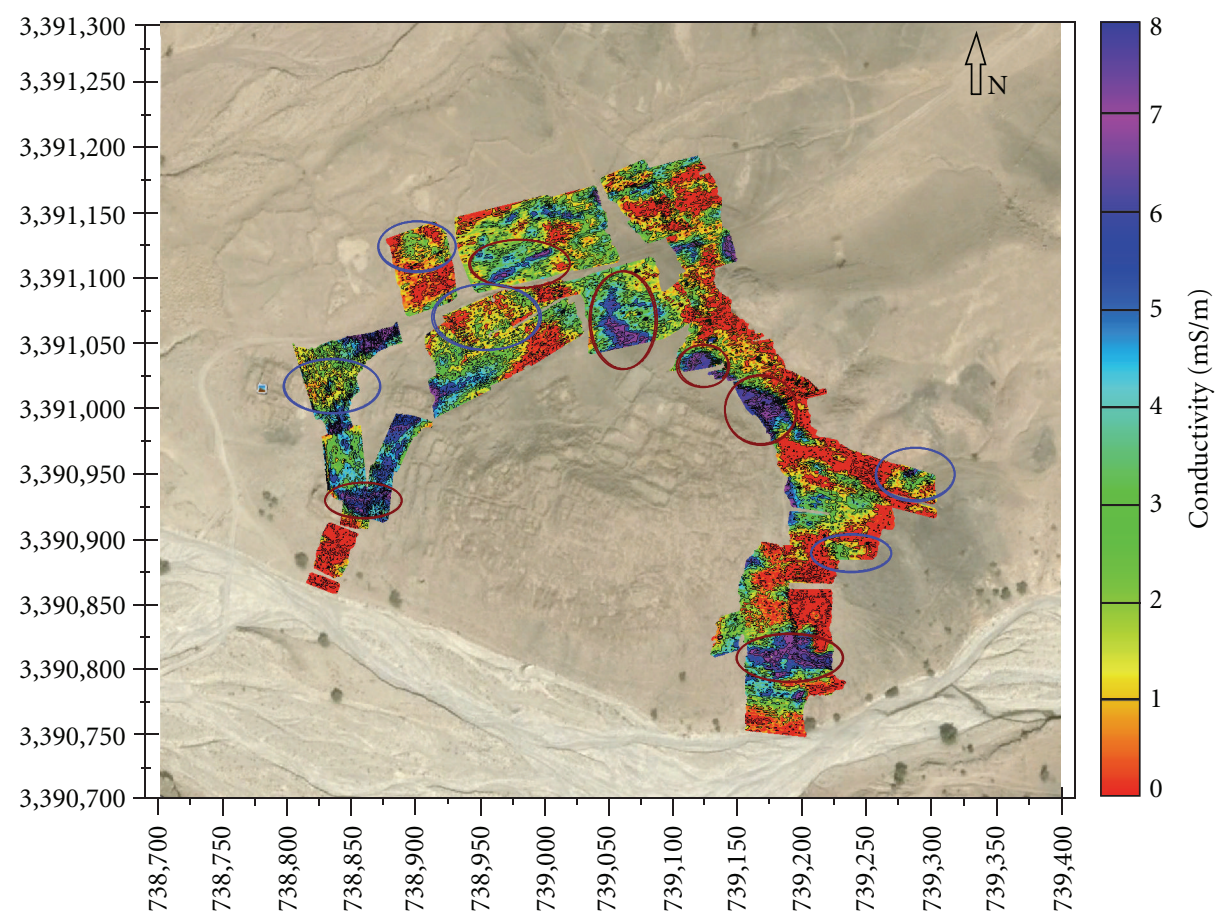

Figure 3: EMI data acquired at Khirbat Faynan. While numerous ancient walls can be seen on the surface of this site with Google Earth, the geophysics survey aimed at identifying subsurface features suitable for excavation. Blue color ellipses show interesting areas of low conductivity. Brown color ellipses indicate areas of high conductivity that might be related to past human activity. The site measures approximately $270 \times 640$ meters.

We first used EMI, requiring no direct contact with the ground surface, which allowed us to survey large areas quickly even with the difficult terrain. We then selected locations to perform ERT dipole-dipole profiles across the site in order to obtain vertical cross sections of the first 5 meters depth. These data were inverted to obtain $2 \mathrm{D}$ electrical images. Finally, we selected an appropriate place to perform a high-resolution 3D mesh. The 3D electrical image obtained from these data was used to decide the location of the season's excavation.

2.1. EMI Equipment and Discussion. Among many applications, electromagnetic induction instruments are used for near-surface archaeological investigations, the detection of buried structures, such as building foundations as well as for the detection of highly conductive metallic objects. EMI was, therefore, used in this study to attempt to locate buried remains of past human activity in the lower flat areas of Khirbat.

The system used in this campaign is a Profiler EMP400 (GSSI, USA) that is a digital, portable, multifrequency electromagnetic induction sensor. The system bandwidth extends from $1 \mathrm{kHz}$ to $16 \mathrm{kHz}$. The system collects three different frequencies simultaneously. The in-phase and quadrature components of the induced secondary field as well as the apparent conductivity are collected and stored for each reading along with a time stamp. GPS data, in the form of a NMEA string, were also recorded for every line.
The system sensor electronics are controlled via a wireless Bluetooth communications interface. The system user interface and data storage are incorporated into a TDS RECON-400 personal digital assistant (PDA) provided with the system. This instrument is easy to use in the field, and the operator can cover several hectares in a week (Figure 2). Due to extremely rough topography, some areas were not scanned.

We studied an area of approximately 6 ha. The system was calibrated every day before starting the data acquisition. Data were collected in rectangular grids of parallel lines spaced $1 \mathrm{~m}$ apart. After marking the grid corners, two measuring tapes were placed in the shorter pair of parallel sides of the grid for measuring the $1 \mathrm{~m}$ spacing between the two survey tapes to mark the exact profile location. The surveyor precisely followed a string in order to ensure straight profiles. For data acquisition consistency, the same person collected all EMI datasets. Field system calibration was a crucial requirement for every survey grid because of extreme temperature changes during data acquisition as well as variable topography across the site.

After collection, data were sent to Geostudi Astier (Livorno, Italy) for processing. First, data trajectories were corrected for spurious GPS points in order to properly align the profiles. Therefore, and second, the data were gridded in MVS/EVS (CTech, USA) using the Kriging algorithm [30]. Finally, the processed results were then sent back to us to be incorporated in the project's geodatabase [31]. The rapid 


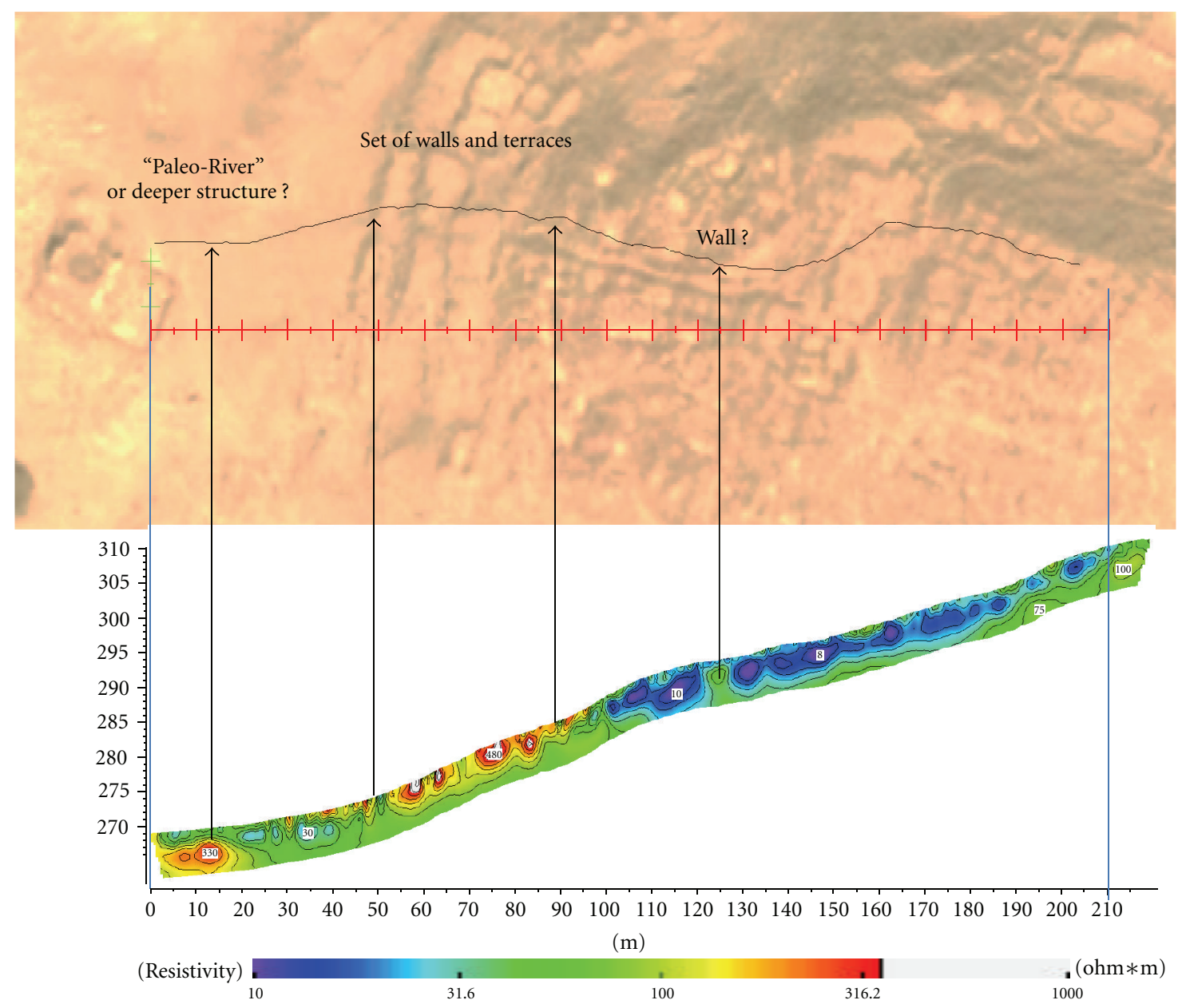

FIgURE 4: 2D ERT line in the west side of the ancient mound.

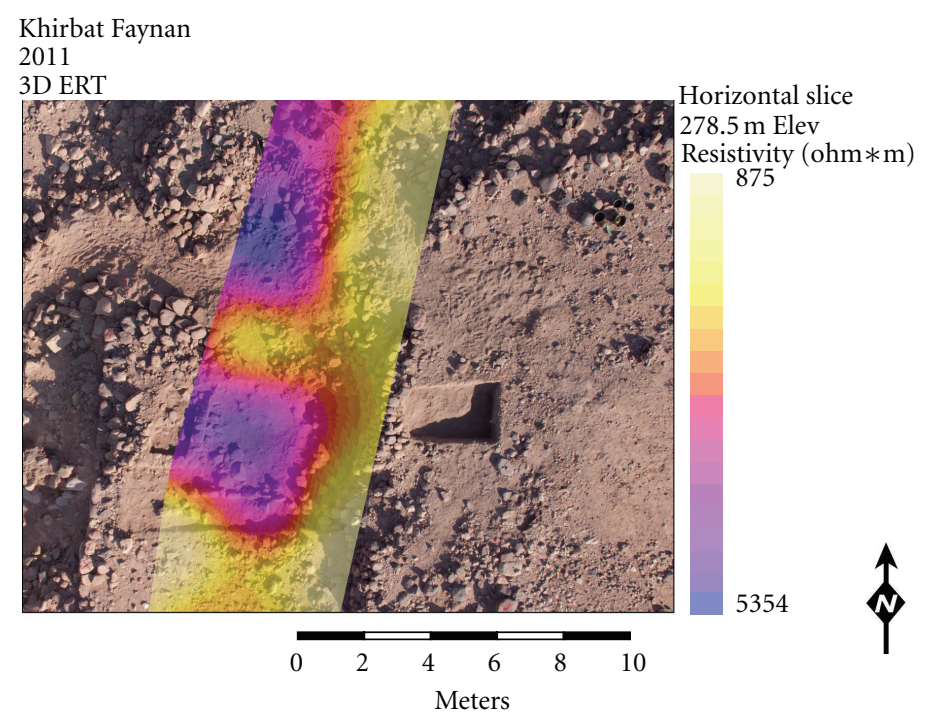

FIgURE 5: Semitransparent horizontal ERT slice at $1 \mathrm{~m}$ depth, overlaid on top of an aerial image of the excavation. 


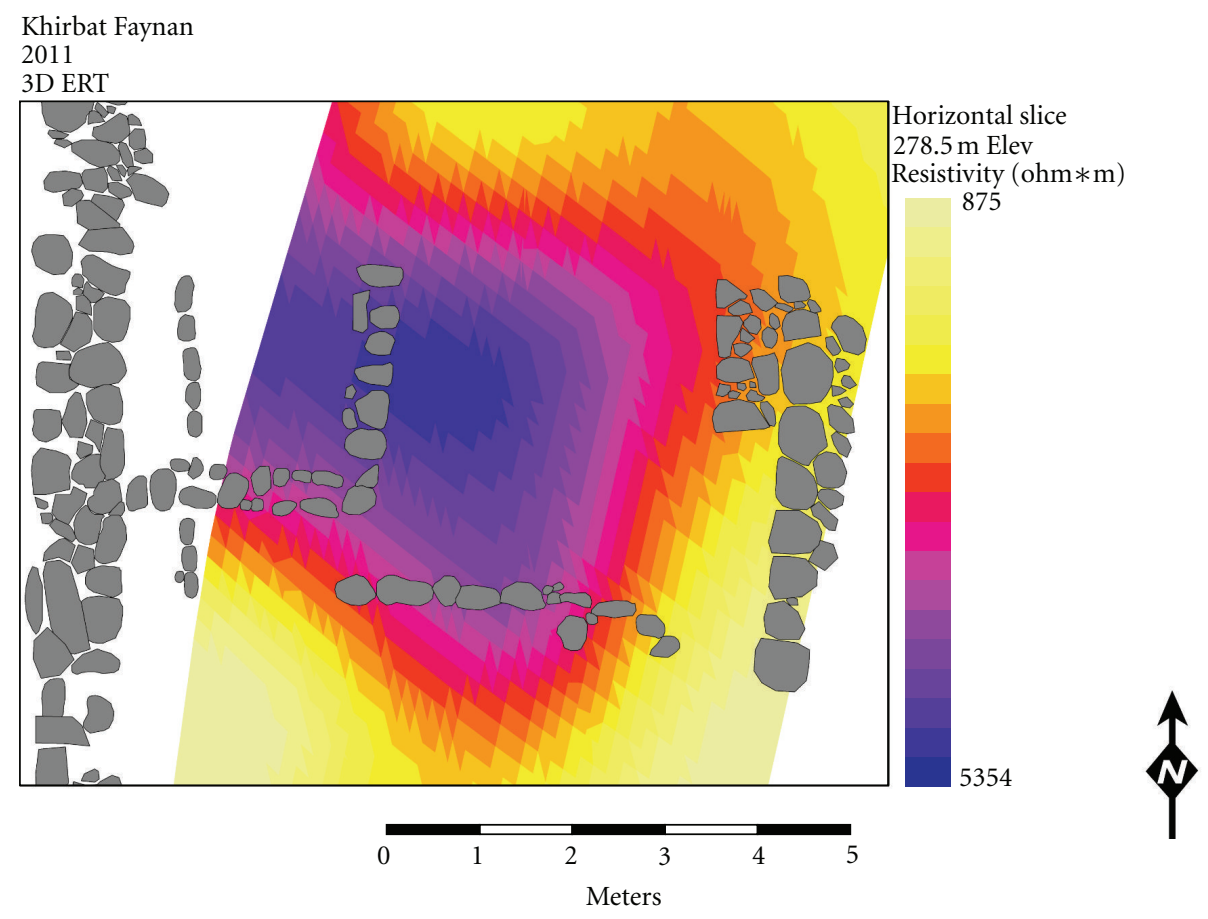

FIGURE 6: Walls found during the excavation superimposed on a horizontal ERT slide at $1 \mathrm{~m}$ depth.

processing allowed for minor adjustments to be made in the survey planning, prioritizing areas with greater potential and leaving areas where there was clearly no subsurface cultural remains.

\subsection{ERT Equipment and Discussion. We used a Syscal Pro} resistivimeter (Iris Instruments, France) with 48 electrodes spaced by 0.5 meters. Four different sets of 2D ERT lines ( 24 electrodes at $1 \mathrm{~m}$ separation each) were collected over 4 sides (north, south, east, and west) of the Khirbat Faynan mound. The main objective was to obtain vertical sections up to 6 meters along the mound in order to investigate the different layers and distinguish cultural from natural layers.

Additionally, a small 3D ERT survey was collected in order to facilitate excavation. The 3D ERT survey used a set of parallel $2 \mathrm{D}$ profiles with a separation of $0.5 \mathrm{~m}$ among electrodes. The surveyed area of $24 \mathrm{~m} \times 5 \mathrm{~m}$ included 6 ERT profiles. Both dipole-dipole and Wenner arrays were performed.

Data acquisition proved to be particularly challenging due to the extremely dry soil, preventing electrical conductivity, and abundance of rocks under the surface, impeding easy introduction of the metal stakes into the ground. While the later was not easily overcome, the former was improved through a mixture of water, clay, and salt producing a remarkably conductive medium which could be poured over each electrode.

After collection, data were sent to Geostudi Astier (Livorno, Italy) for inversion using ERTLab software (MultiPhase Technologies LLC, USA and Geostudi Astier srl, Italy) and generation of final maps within the software MVS/EVS (CTech, USA) and ArcMap 10 (ESRI, USA). The main purpose of the 3D ERT survey was to delineate buried stonewalls to guide archaeological excavations.

In our processing, full three-dimensional inversions of apparent resistivities are performed using a specific customized tool, derived from the ERTLab 3D inversion software, which uses a finite-element (FEM) approach to model the subsoil by adopting mesh of hexahedrons to correctly incorporate terrain topography [32]. Throughout the inversion iterations, the effect of non-Gaussian noise is appropriately managed using a robust data weighting algorithm $[33,34]$.

This past season, new benchmarks were placed around and on top of the tell with an RTK GPS system to ensure precise control of the surveying. Unlike EMI, the ERT has no self-georeferencing system. Therefore, the ERT was georeferenced using a reflectorless total station, which could measure the precise position of the stakes with or without a prism. Each individual line was shot in its entirety in order to provide redundancy when the lines were then matched up during the postprocessing. Since GIS has been a major component of the ELRAP field recording system since 1999 [35], there was already an infrastructure in place to relate the geophysical data with the archaeological data. As part of this recording system, daily aerial photographs are taken documenting the position of significant architectural features. Each photograph can be correlated with the daily elevations to know exactly what the elevations of the exposed layers are. This enabled us to lay the 3D ERT slices that corresponded to each aerial photograph's elevation in order to study the relationship of the geophysics with the archaeological record. 


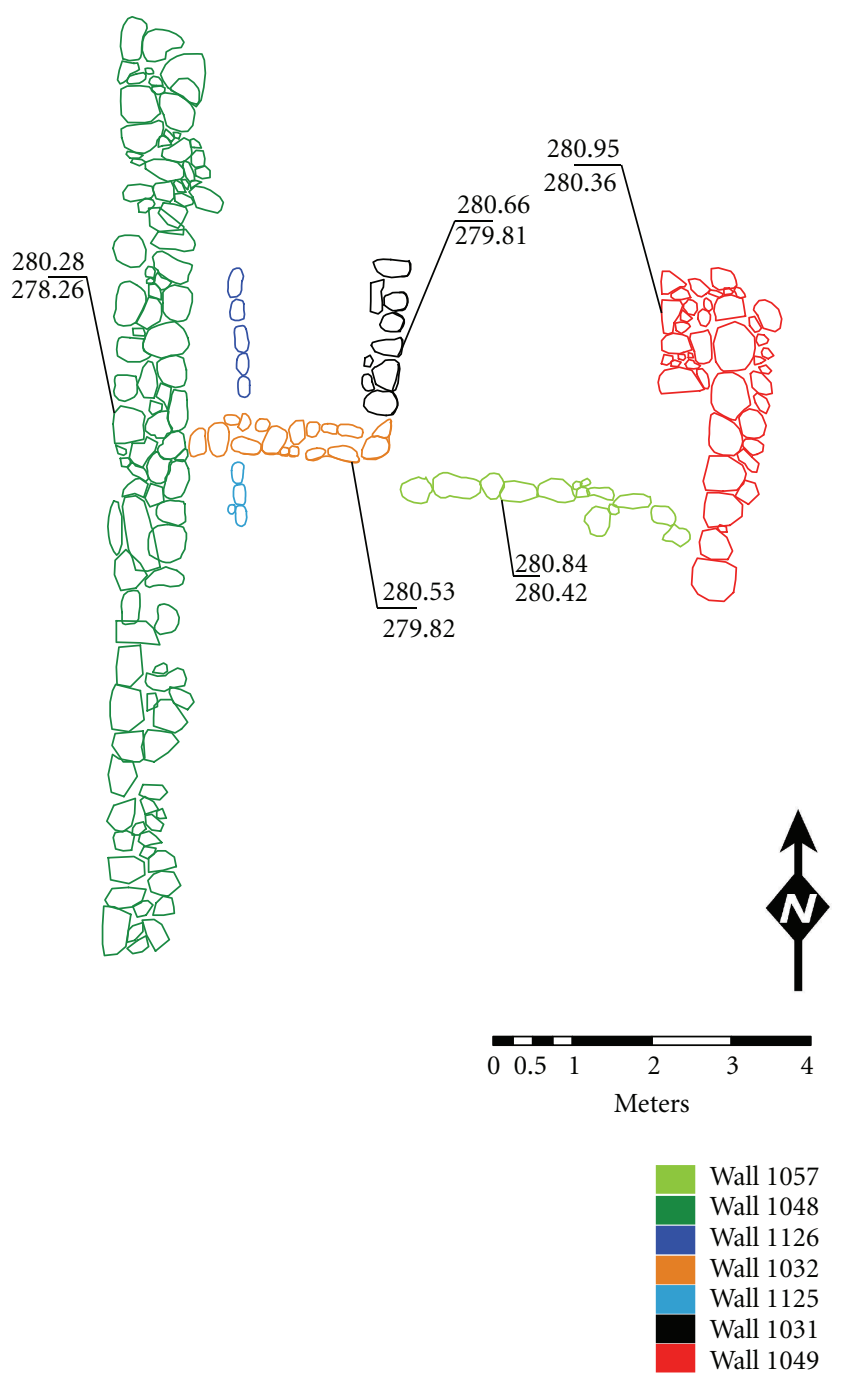

FIGURE 7: Ground truth, archaeological plan of the excavated walls detected using the 3D ERT geophysics.

\section{Discussion}

No features suggesting buried structures appeared in the lower-frequency EMI data. For this reason, EMI results presented here are for the higher $(15 \mathrm{kHz})$ operating frequency (Figure 3 ). The most interesting areas, likely related to past human activity, have been highlighted. Some of them show clear linear patterns, other show areas with very high conductivity values (magenta and blue color) which might indicate the presence of accumulated metallurgic production materials. Unfortunately, in some areas, the presence of many pieces of slag covering the surface might have affected the EMI data due to its high sensitivity to metals. Thus, areas with higher conductivity may indicate just places of high concentration of slag covering the surface. However, other areas present subtle features of lower values (green and yellow colors) that may represent walls. As discussed by Witten [17], who worked in similar conditions, buried walls can appear as low values in the EMI data.
Past surveys in the area have included EMI and GPR, but ERT had not yet been employed. The 2D lines have enabled us to characterize the mound and we now have a better idea of the overall archaeological record. While the 2D does not give us a precise picture of the archaeology, it does at least suggest possible depths of archaeological depositions (Figure 4). Because of the lack of ERT performed in the area, it was felt that a ground truthing should be conducted in addition to the survey to correlate the results with the archaeological record. Half of square 16-56 was excavated, an area representing over half of the 3D ERT. The $3 \mathrm{D}$ volume showed what were most likely buried walls underneath the surface (see Figures 5 and 6). On the other hand, the ERT sections and volumes have shown that the very low-conductivity values, between 0 and $1 \mathrm{mS} / \mathrm{m}$, match well with areas where the resistivity is higher than $1000 \mathrm{Ohm} \cdot \mathrm{m}$. Therefore, the ERT sections were used also to verify and calibrate properly the conductivity value in a condition that is typically not favorable for EM induction instruments.

The most significant correlation can be found between walls 1032 and 1057 (Figure 7). Because the lines went from north to south, the east-west walls seem to be the most visible in the data. In other words, every wall crossed is more visible than those running parallel to the survey lines. Wall 1032 was the closer of the two walls to the surface and was also more substantial than wall 1057 which had less preservation, these two factors together likely account for the stronger area of resistivity around wall 1032.

The GIS centric system of archaeological recording employed by the ELRAP team [35] allowed us to closely compare the archaeology with the geophysical survey. We were able to drape the appropriate ERT slices with the corresponding exposures at precise elevations. This allowed us to both compare the results of the excavation alongside the geophysics as well as predict what was coming next through the same sort of comparison. The final results were a series of images (see Figures 5 and 6 ) that show both the archaeology and the geophysics, with the later overlaid over the former. This further highlights the need for accurate georeferencing in geophysical survey, something which was central in our data collection.

\section{Conclusion}

The EMI data give us a general idea of what might be interesting to look at in detail in subsequent seasons in the lower area of the site. Future geophysical surveys should focus on the use of 3D GPR to locate more structures and accurately delineate those suggested by the EMI maps. The use of mobile multicoil EMI systems is also being considered due to their high lateral spatial resolution with accurate vertical measurements [36]. 3D GPR provides high-resolution volumetric data $[14,37,38]$. However, in order to use a GPR system in this area, rocks will have to be cleared from the study surface beforehand. Considering the quantity of rocks strewn about the surface, this will be a difficult task. On the other hand, the high-precision 3D ERT is potentially one of the more useful survey methods for such difficult terrain as 
a rock-strewn tell. The time required to clean the surface of rocks as well as sort out what was tumble and what was part of existing architecture, would have proved far too costly to make it a viable technique for wide-area surveys. Indeed, the 3D ERT is still expensive in terms of human hours required to employ it; however, the technique is much less disturbing with high potential for excellent results.

The results from this season's work suggest that 3D ERT is a useful method for geophysical survey in difficult conditions that prevent the use of GPR. However, future work should include continued 3D ERT survey to conduct further correlation between the data and the archaeological record. Likewise, continued use of EMI can be helpful in revealing promising areas for more precise geophysical survey. With newer instruments, EMI is continuing to increase in precision and could potentially become one of the more useful tools as precision becomes more like that of ERT or GPR. Until such a time, however, EMI surveys like ours do not appear to offer much beyond that of general characterization of subsurface features. Southern Jordan continues to be an ideal place for testing geophysical survey techniques in difficult and harsh environments. The two techniques employed at Khirbat Faynan both resulted in success, each in their own way. We found that EMI helped to guide us towards the regions that we wanted to investigate further with higherprecision survey tools. This saved us countless hours considering the difficulty of employing the ERT versus that of EMI. Ultimately, the two tools together offered the best geophysical kit for our environment.

\section{Acknowledgments}

The authors are grateful to the Department of Antiquities (DOA) of Jordan for its help and interest in the 2011 ELRAP expedition. In particular, Jehad Haroun, Khalil Hamdan, Qutaiba al-Dasouqi, and especially Abdelrahim Al Dwikat and Zouhair Zoubi who served as DOA representatives to our project. Thanks also to Barabara Porter (director) and Christopher Tuttle (associate director) of the American Center of Oriental Research (ACOR), Amman, for their help and support. Members of most of the Bedouin tribes from the Qurayqira/Faynan villages worked on the project. Funding for this project came from: Research Opportunities (CSRO) Grant program; NSF grant EAR-Geophysics, 09539; National Geographic Society (Grant no. 8974-11), the Jerome and Miram Katzin Family Foundation, and the Norma and Reuben Kershaw Family Foundation. M. Vincent was supported by the National Science Foundation IGERT (Integrative Graduate Education and Research): Training, Research and Education in Engineering for Cultural Heritage Diagnostics (NSF 0966375), where T. E. Levy serves as coPI. A special thanks to Ramesh Rao, director, Calit2 San Diego Division for his support of the ELRAP expedition. They deeply appreciate the hard work carried out by the undergraduate students enrolled in the UCSD Middle East Archaeology Field School that forms part of the ELRAP research endeavor. The 2011 ELRAP expedition was directed by T. E. Levy and Mohammand Najjar. They thank M. Najjar for his collegiality and interaction in the field. Thanks also to Gianfranco Morelli, Geostudi Astier, for help with data processing.

\section{References}

[1] R. Slatt, W. C. King, J. Molyneux et al., "Tribute to Dr. Alan Witten," Earth Scientist, pp. 9-23, 2005.

[2] A. J. Witten, Handbook of Geophysics and Archaeology, Equinox Pub, 2006.

[3] T. E. Levy, T. Higham, C. B. Ramsey et al., "High-precision radiocarbon dating and historical biblical archaeology in southern Jordan," Proceedings of the National Academy of Sciences of the United States of America, vol. 105, no. 43, pp. 16460-16465, 2008.

[4] E. Ben-Yosef, T. E. Levy, T. Higham, M. Najjar, and L. Tauxe, "The beginning of Iron Age copper production in the southern Levant: new evidence from Khirbat al-Jariya, Faynan, Jordan," Antiquity, vol. 84, no. 325, pp. 724-746, 2010.

[5] E. Ben-Yosef, T. E. Levy, and M. Najjar, "Rās al-Miyāh fortresses: new discoveries at one of the gateways to the iron age copper production district of Faynan, Jordan," pp. 832-841, 2009.

[6] E. Ben-Yosef, T. E. Levy, and M. Najjar, "New iron age coppermine fields discovered in southern Jordan," Near Eastern Archaeology, vol. 72, no. 2, pp. 98-101, 2009.

[7] T. E. Levy, E. Ben-Yosef, and M. Najjar, "New perspectives on iron age copper production and society in the Faynan Region, Jordan," in Eastern Mediterranean Metallurgy and Metalwork in the Second Millenium BC, V. Kassianidou, Ed., Oxbox Books, Oxford, UK, 2012.

[8] G. Barker, D. D. Gilbertson, and D. J. Mattingly, Archaeology and Desertification: The Wadi Faynan Landscape Survey, Southern Jordan, Oxbow, 2007.

[9] C. E. Cordova, Millennial Landscape Change in Jordan: Geoarchaeology and Cultural Ecology, The University of Arizona Press, 2007.

[10] A. Hauptmann, The Archaeometallurgy of Copper: Evidence from Faynan, Jordan, Springer, 2007.

[11] J. P. Grattan, D. D. Gilbertson, and C. O. Hunt, "The local and global dimensions of metalliferous pollution derived from a reconstruction of an eight thousand year record of copper smelting and mining at a desert-mountain frontier in southern Jordan," Journal of Archaeological Science, vol. 34, no. 1, pp. 83-110, 2007.

[12] C. O. Hunt, D. D. Gilbertson, and H. A. El-Rishi, "An 8000year history of landscape, climate, and copper exploitation in the Middle East: the Wadi Faynan and the Wadi Dana National Reserve in southern Jordan," Journal of Archaeological Science, vol. 34, no. 8, pp. 1306-1338, 2007.

[13] B. W. Bevan, "Geophysical exploration for archaeology: an introduction to geophysical exploration," Midwest Archaeological Center Special Report 1, U.S. Department of the Interior, National Park Service, Lincoln, Neb, USA, 1998.

[14] L. B. Conyers and D. Goodman, Ground-Penetrating Radar: An Introduction for Archaeologists, AltaMira Press, 1997.

[15] C. Gaffney, "Detecting trends in the prediction of the buried past: a review of geophysical techniques in archaeology," Archaeometry, vol. 50, no. 2, pp. 313-336, 2008.

[16] K. L. Kvamme, "Geophysical surveys as landscape archaeology," American Antiquity, vol. 68, no. 3, pp. 435-457, 2003. 
[17] A. J. Witten, T. E. Levy, R. B. Adams, and I. Won, "Geophysical surveys in the Jebel Hamrat Fidan, Jordan," Geoarchaeology, vol. 15, no. 2, pp. 135-150, 2000.

[18] D. Simpson, A. Lehouck, M. Van Meirvenne, J. Bourgeois, E. Thoen, and J. Vervloet, "Geoarchaeological prospection of a medieval manor in the Dutch polders using an electromagnetic induction sensor in combination with soil augerings," Geoarchaeology, vol. 23, no. 2, pp. 305-319, 2008.

[19] A. Tabbagh, "Applications and advantages of the Slingram electromagnetic method for archaeological prospecting," Geophysics, vol. 51, no. 3, pp. 576-584, 1986.

[20] B. Frohlich and W. J. Lancaster, "Electromagnetic surveying in current Middle Eastern archaeology: application and evaluation.," Geophysics, vol. 51, no. 7, pp. 1414-1425, 1986.

[21] A. Witten, G. Calvert, B. Witten, and T. Levy, "Magnetic and electromagnetic induction studies at archaeological sites in Southwestern Jordan," Journal of Environmental and Engineering Geophysics, vol. 8, no. 3, pp. 209-215, 2003.

[22] M. Dabas, A. Hesse, and J. Tabbagh, "Experimental resistivity survey at Wroxeter archaeological site with a fast and light recording device," Archaeological Prospection, vol. 7, no. 2, pp. 107-118, 2000.

[23] I. Scollar, A. Tabbagh, A. Hesse, and I. Herzog, Archaeological Prospecting and Remote Sensing, Cambridge University Press, Cambridge, UK, 1990.

[24] M. Drahor, M. Berge, and Ö. Caner, "Integrated geophysical surveys for the subsurface mapping of buried structures under and surrounding of the Agios Voukolos Church in Izmir, Turkey," Journal of Archaeological Science, vol. 38, no. 9, pp. 2231-2242, 2001.

[25] S. Negri, G. Leucci, and F. Mazzone, "High resolution 3D ERT to help GPR data interpretation for researching archaeological items in a geologically complex subsurface," Journal of Applied Geophysics, vol. 65, no. 3-4, pp. 111-120, 2008.

[26] G. N. Tsokas, P. I. Tsourlos, G. Vargemezis, and M. Novack, "Non-destructive electrical resistivity tomography for indoor investigation: the case of Kapnikarea Church in Athens," Archaeological Prospection, vol. 15, no. 1, pp. 47-61, 2008.

[27] P. I. Tsourlos and G. N. Tsokas, "Non-destructive electrical resistivity tomography survey at the South Walls of the Acropolis of Athens," Archaeological Prospection, vol. 18, no. 3, pp. 173-186, 2011.

[28] J. Casana, J. T. Herrmann, and A. Fogel, "Deep subsurface geophysical prospection at Tell Qarqur, Syria," Archaeological Prospection, vol. 15, no. 3, pp. 207-225, 2008.

[29] A. Osella, M. de la Vega, and E. Lascano, "3D electrical imaging of an archaeological site using electrical and electromagnetic methods," Geophysics, vol. 70, no. 4, pp. G101-G107, 2005.

[30] G. Matheron, "Principles of geostatistics," Economic Geology, vol. 58, no. 8, pp. 1246-1266, 1963.

[31] T. E. Levy, M. Najjar, A. D. Gidding et al., "The 2011 Edom Lowlands Regional Archaeology Project (ELRAP): Excavations and Surveys in the Faynan Copper Ore District, Jordan," Annual of the Department of Antiquities of Jordan.

[32] Z. Bing and S. A. Greenhalgh, "Finite element three-dimensional direct current resistivity modelling: accuracy and efficiency considerations," Geophysical Journal International, vol. 145, no. 3, pp. 679-688, 2001.

[33] D. J. LaBrecque, M. Miletto, W. Daily, A. Ramirez, and E. Owen, "The effects of noise on Occam's inversion of resistivity tomography data," Geophysics, vol. 61, no. 2, pp. 538-548, 1996.
[34] G. Morelli and D. J. Labrecque, "Advances in ERT inverse modeling," European Journal of Environmental and Engineering Geophysics, vol. 1, no. 2, pp. 171-186, 1996.

[35] T. Levy, V. Petrovic, T. Wypych et al., On-Site Digital Archaeology 3.0 and Cyber-Archaeology: Into the Future of the Past-New Developments, Delivery and the Creation of a Data Avalanche, Introduction to Cyber-Archaeology, Archaeopress, Oxford, UK, 2010.

[36] P. De Smedt, M. Van Meirvenne, E. Meerschman et al., "Reconstructing palaeochannel morphology with a mobile multicoil electromagnetic induction sensor," Geomorphology, vol. 130, no. 3-4, pp. 136-141, 2011.

[37] J. Leckebusch, "Ground-penetrating radar: a modern threedimensional prospection method," Archaeological Prospection, vol. 10, no. 4, pp. 213-240, 2003.

[38] A. Novo, M. Grasmueck, D. Viggiano, and H. Lorenzo, “3D GPR in archaeology: what can be gained from dense data acquisition and processing," in Proceedings of the 12th International Conference on Ground Penetrating Radar, pp. 16-19, 2008. 

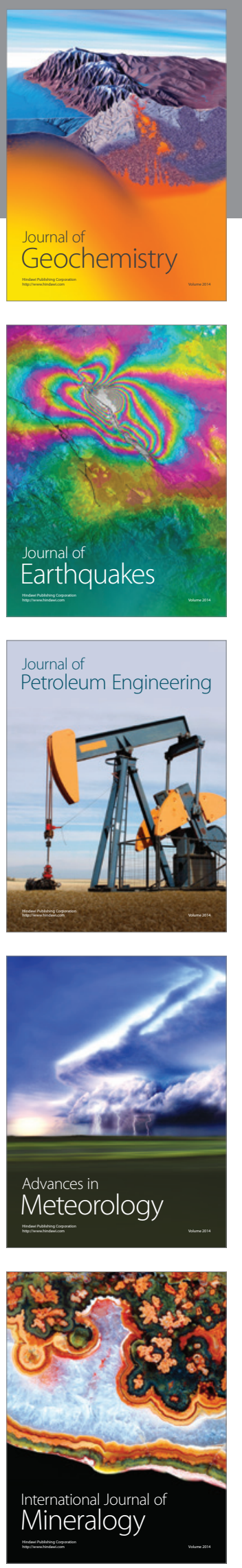
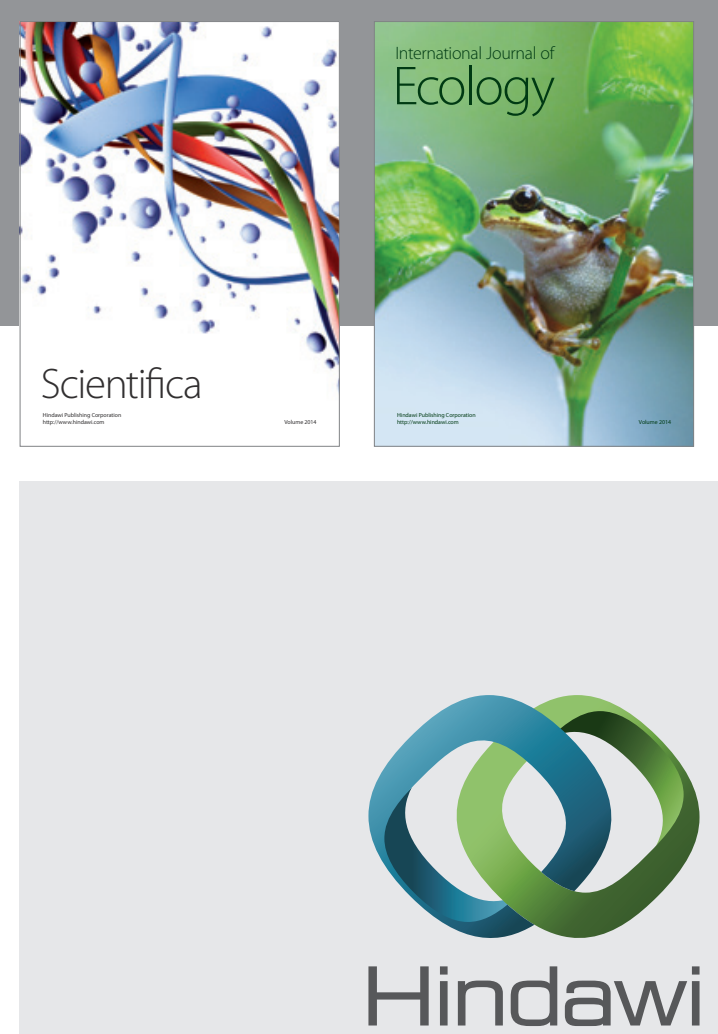

Submit your manuscripts at http://www.hindawi.com
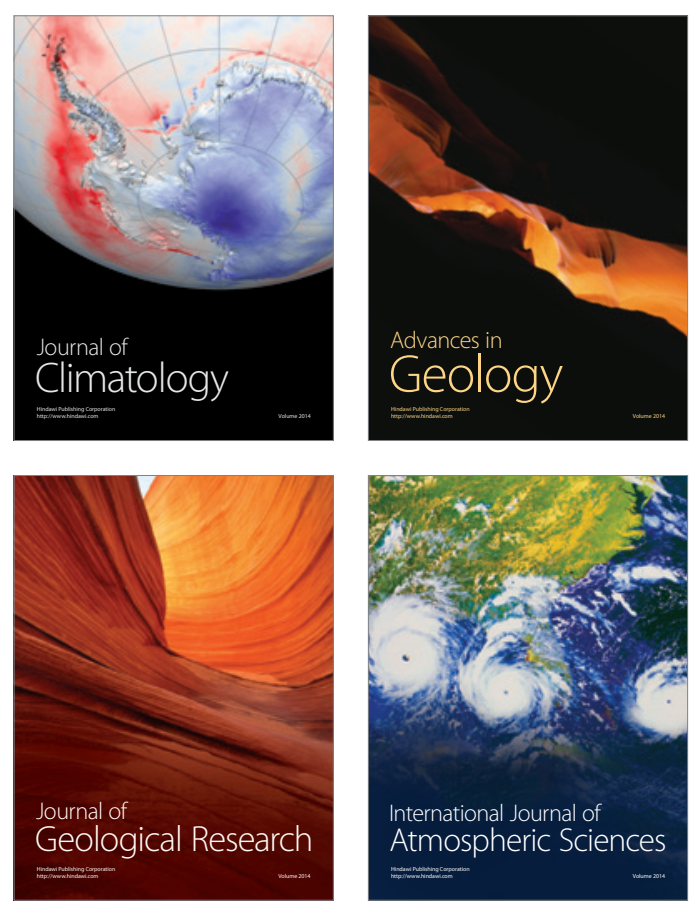
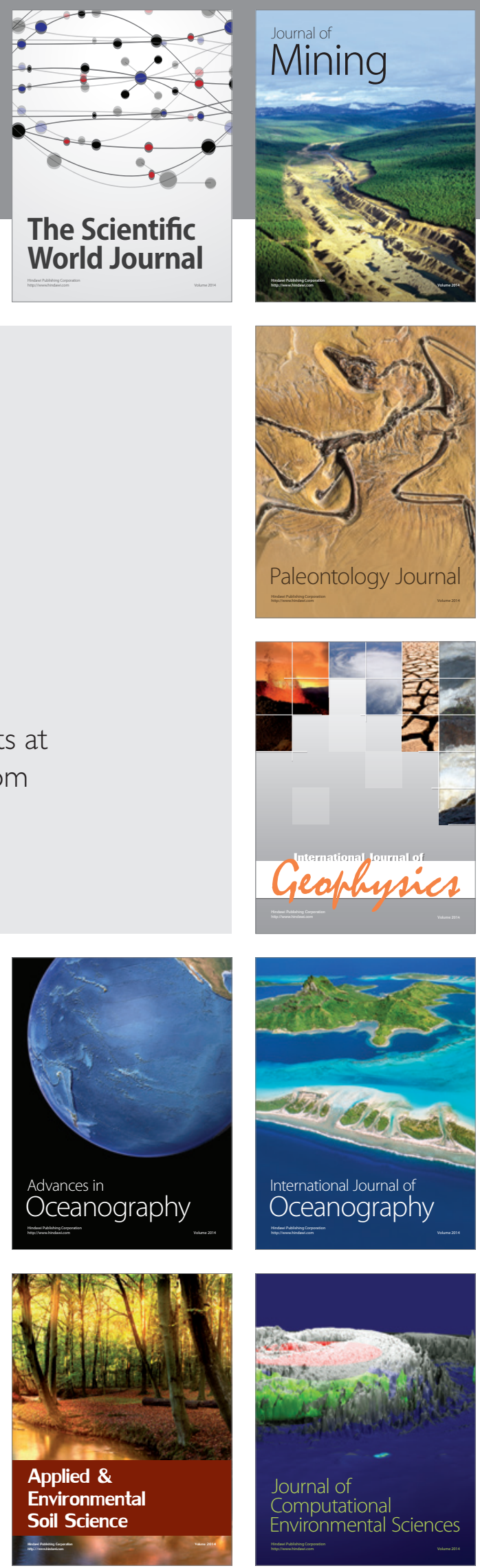